\title{
The Threshold Effects of RMB Exchange Rate Fluctuations on Imports and Exports
}

\author{
Chuanglian Chen \\ School of Economics and Management, South China Normal University, Guangzhou, China \\ Email: alisdent@yahoo.com.cn \\ Received March 10 $0^{\text {th }}, 2012$; revised April 27 $7^{\text {th }}, 2012$; accepted May $18^{\text {th }}, 2012$
}

\begin{abstract}
Using threshold panel model, we estimate the effectiveness of exchange rate to imports and exports. We conclude that there is a second threshold in both import and export regression models, and China's trade flows don't accord with ML condition, when RMB exchange rate appreciation is less than $7.8 \%$. Whereas, when higher than $7.8 \%$, the ML condition strongly holds, indicating that the RMB exchange rate appreciation would deteriorate the China's international revenue. As RMB exchange rate to US dollar has experiences an appreciation of $22.2 \%$ from 2005Q3 to 2012Q1, thus China's current account would be deteriorated. Therefore, some changes or policies should be made to deal with these problems.
\end{abstract}

Keywords: Threshold Effects, Exchange Rate, Imports, Marshall-Lener Condition

\section{Introduction}

On July 21, 2005, the People's Bank of China makes a decision that the exchange rate regime was changed from a de facto peg to the US dollar to a more flexible peg to a basket of foreign currencies. And on April 16, 2012, the PBC relaxes exchange rate fluctuations bands to $1 \%$. As to this, the RMB exchange rate to US dollar has experiences an appreciation of $22.2 \%$ from 2005Q3 to 2012Q1. According to the traditional elasticity theory, the exchange rate appreciation will lower exports and increase imports. Moreover, if the Marshall-Lerner condition holds, exchange rate (domestic currency) appreciation would deteriorate international revenue and devaluation will improve the net trade flows.

The elasticity approach is still the most commonly used in balance of trade flows analysis. Recently, a large body of literatures has reexamined the impact of exchange rate fluctuations on the balance of trade through examining the ML condition from a theoretical point of view. Oskooee-Bahmani (1998), Bahmani-Oskooee and Kara (2003), De Silva and Zhu(2004) et al. find that most countries' trade elasticities are large enough to support devaluation as a successful policy for improving the balance of trade flows. Whereas, Wilson (2001) concludes that there is no J-curve for Malaysia, Korea and Singapore, and the ML conditions is not met. Luis Sastre (2012) also supports this conclusion for other countries.

As to most domestic studies, the related empirical studies can be classified into three categories. First, Li Yining (1991) argues that the demand elasticities of imports and exports are insufficient. Second, the elasticities of exchange rate to trade flows only reaches the critical value, thus the effect of exchange rate fluctuations to China's trade is relatively small (Chen, 1992). Third, most recently empirical literatures show that ML condition holds in China (Dai, 1997; Feng, 2007; Liu, Zhou, \& Xu, 2010).

Although the conclusions are different in the above studies, but all of them use linear model as an application. As the impacts of exchange rate variations on imports and exports may be non-linear, therefore, we employ the threshold panel model, proposed by Hansen $(1996,1999)$, to estimate the threshold effects. And then, analyze different threshold effects of exchange rate variations to imports and exports. From the empirical conclusions, we not only can test the effective of exchange rate appreciation on trade, but also examine how large the exchange rate can appreciation, and wouldn't deteriorate trade flows.

\section{Theoretical Model and Threshold Panel Regression Model}

\section{Theoretical Model}

Following the recent literature, we assume that the main determinants of a country's exports and imports are income, relative prices and trade cost. Thus, we assume that exports and import demand function for each country take the form of $E X=E X\left(Y^{*}, P X, P X^{*}, T, E\right)$ and $I M=I M(Y, P M, P D, T, E)$, where $E X$ and $I M$ stand for exports and imports, respectively. $Y$ is China's income, and $Y^{*}$ is trade partners' income. $P M$ stands for import price, $P D$ stands for domestic price, $T$ denotes trade cost, $E$ denotes exchange rate, $P X$ is export price, $P X^{*}$ is trade partners' export price. Consider $P D=P X=P$, where $P$ is domestic price. $P M=P X^{*}=P^{*}$, where $P^{*}$ is trade foreign partners' domestic price.

In order to estimate the effect of exchange rate to imports and exports, as $E=S \times P^{*} / P$, where $S$ denotes the bilateral nominal exchange rate. Following the literature, we assume that the rest of the trade partners' demand for a country's exports (ex) and imports (im) take the following log-form:

$$
\begin{aligned}
& e x_{t}=\alpha_{e x}+\beta_{e x} y_{t}^{*}+\delta t_{i t}+\lambda_{e x} e_{t} \\
& i m_{t}=\alpha_{i m}+\beta_{i m} y_{t}+\delta t_{i t}+\lambda_{i m} e_{t}
\end{aligned}
$$

where, the lowercase letters represent the logarithmic form of the corresponding capital letters. As for the model, domestic currency (exchange rate) appreciation would increase imports if 
$\lambda_{i m}>0$, and exchange rate appreciation would reduce exports if $\lambda_{e x}<0 . \delta<0$ denotes that trade cost would reduce both imports and export. $\beta_{i m}>0$ indicates that the improvement of the domestic income would increase imports, however, if the domestic income is increased by imports substitution, then $\beta_{i m}<0 . \beta_{e x}>0$ indicates that the improvement of the foreign trade partners' income would increase exports, however, if income is increased by exports substitution, then $\beta_{e x}<0$ (Kara, 2002). Furthermore, the Marshall-Lener condition holds if $\left|\lambda_{i m}\right|+\left|\lambda_{e x}\right|>1$.

\section{Threshold Panel Regression Model}

In order to capture whether there is a structural change relationship between dependent variable and independent variables. We use threshold panel regression model, proposed by Hansen (1996, 1999), as an application. Consider a threshold panel regression model based on Equations (1) and (2),

$$
\begin{aligned}
e x_{t}= & \alpha_{e x}+\beta_{e x} y_{t}^{*}+\delta t_{i t}+\lambda_{e x}^{1} e_{t} \cdot I\left(q_{i t} \leq \gamma\right) \\
& +\lambda_{e x}^{2} e_{t} \cdot I\left(q_{i t}>\gamma\right)+\varepsilon_{t} \\
i m_{t}= & \alpha_{i m}+\beta_{i m} y_{t}+\delta t_{i t}+\lambda_{i m}^{1} e_{t} \cdot I\left(q_{i t} \leq \gamma\right) \\
& +\lambda_{i m}^{2} e_{t} \cdot I\left(q_{i t}>\gamma\right)+\varepsilon_{t}
\end{aligned}
$$

where, $q_{i t}$ is the threshold variable, representing the growth ratio of exchange rate. $I(\cdot)$ denotes a Heaviside function, indicating that $I\left(q_{i t} \leq \gamma\right)=1$ when $q_{i t} \leq \gamma$, otherwise,

$I\left(q_{i t}>\gamma\right)=0$. Equation (3) and (4) are estimated according to Hansen (1999). When $\gamma$ is known, we use ordinary fixed effect regression model to estimate the values of $\lambda_{e x}^{1}$ and $\lambda_{e x}^{2}$ or $\lambda_{i m}^{1}$ and $\lambda_{i m}^{2}$, and the corresponding sum of squared errors is $S_{1}(\gamma)$. However, if $\gamma$ is un-known, Chan (1993) and Hansen (1997) recommend estimation of $\gamma$ by least-squares when non-linear specification of Equation (3) and (4). This is easiest to achieve by minimization of the concentrated sum of squared errors. Hence the least-squares estimators of $\gamma$ is

$$
\hat{\gamma}=\arg \min _{\gamma} S_{1}(\gamma)
$$

The minimizing sum of squared errors from Equation (5) is $S_{1}(\gamma)$ with variance estimate

$$
\hat{\sigma}^{2}=S_{1}(\hat{\gamma}) /[n(T-1)]
$$

Then, we have to test whether there is a threshold effect. Hansen $(1996,1999)$ provides a hypothesis test, $H_{0}: \lambda_{e x}^{1}=\lambda_{e x}^{2}$, $H_{1}: \lambda_{e x}^{1} \neq \lambda_{e x}^{2}$ or $H_{0}: \lambda_{i m}^{1}=\lambda_{i m}^{2}, H_{1}: \lambda_{i m}^{1} \neq \lambda_{i m}^{2}$. Thus an approximate likelihood ratio test of zero versus single threshold can be based on the statistic

$$
F_{1}=\left[S_{0}-S_{1}(\hat{\lambda})\right] / \hat{\sigma}^{2}
$$

where $S_{0}$ denotes the sum of squared errors when null hypothesis holds. The hypothesis of no threshold is rejected in favor of single threshold if F1 is large. As is pointed by Hansen (1999), since the null asymptotic distribution of the likelihood ratio test is non-pivotal, we suggest using a bootstrap procedure to approximate the sampling (empirical) distribution, and then derive the bootstrap asymptotic and efficient $p$-value of the according F-value under H0. The null of no threshold effect is rejected if the $p$-value is smaller than the desired critical value. Furthermore, Hansen (1996) proves that the statistic $p$-value obeys uniform distribution in the large sample, and can be de- rived through bootstrap.

Finally, we consider the construction of confidence intervals for the threshold parameters, and then test whether the estimated value of the threshold is a consistent estimator. Due to the nuisance parameters, the traditional statistics would be nonstandard. In order to overcome this problem, Hansen (1999) constructs a "no-rejection region" of asymptotic and efficient confidence interval using the maximum likelihood ratio LR statistics. Thus we can construct confidence interval to be

$$
\operatorname{LR}_{1}^{\gamma}(\gamma)=\left[S_{1}(\gamma)-S_{1}\left(\hat{\gamma}_{1}\right)\right] / \hat{\sigma}^{2}
$$

Our asymptotic $(1-\alpha) \%$ confidence interval for $\gamma_{1}$ is the set of values of $\gamma$ such that $L R(\gamma) \leq-2 \log (1-\sqrt{1-\alpha})$. One of the convenient features of this confidence region is that it's a natural by-product of model estimation. The likelihood ratio sequence LR is a simple re-normalization of these numbers, and require no further computation. The above mode only considers single threshold condition. In some applications there may be multiple thresholds. In these cases we can use similar method to search for the two or more threshold values, pointed out and discussed by Hansen (1999).

\section{Empirical Results and Analysis}

\section{Data Sources}

This paper uses data from 1995Q1 to 2009Q3 for China export to and import from 30 countries and regions ${ }^{1}$, and quarterly data are seasonally adjusted by X-12ARIMA. The bilateral real exchange rate is derived by $B R E R=N R E R \times C P I^{*} / C P I$, where NRER denotes bilateral nominal exchange rate, CPI is the China's consumer price index (with 2005 as the base year) and $C P I^{*}$ is the trading partners' consumer price index (with 2005 as the base year). The trade cost is derived by the following equation according to Novy (2006),

$$
T_{i, j}=1-\left(x_{i, j} x_{j, i} /\left[\left(G D P_{i}-x_{j}\right)\left(G D P_{j}-x_{i}\right) s^{2}\right]\right)^{1 /(2 \rho-2)}
$$

where, $x_{i, j}$ denotes the exports of country $i$ to country $j$. $G D P_{i}$ denotes the GDP of country $i . x_{i}$ denotes the exports of country $i$. All the data, exports, imports, GDP, bilateral nominal exchange rate, and consumer price index, are collected from China's Economic Internet Database and CEIC Global Database. The descriptive statistics of the selected variables are in Table 1.

\section{Panel Unit Root Test and Panel Cointegration Test}

The first step is to check for the stationary properties of the variables involved. Table 2 represents the results of the panel unit root tests. The level variables have been specified with individual intercept and trend, and the first difference variables are specified with individual intercept in the tests. A unit root is detected for the level variables, while the first differences appear to be stationary. We conclude that each variable includes a random walk component.

${ }^{1} 30$ countries and regions include Argentina, Austria, Australia, Brazil, Belgium, Denmark, German, Russia, French, Philippines, Finland, Kazakhstan, Korea, Holland, Canadian, Malaysia, USA, Japan, Swedish, Swiss, Taiwan, Thailand, Spain, Hong Kong, New Zealand, Iran, Italy, Indonesia, UK, and Chile. 
Table 1.

Summary statistics.

\begin{tabular}{cccccc}
\hline V. & Obs. & Mean & Std. Dev. & Min. & Max. \\
\hline$e x$ & 1740 & 2.281 & 1.610 & -3.083 & 6.115 \\
$i m$ & 1740 & 2.054 & 1.509 & -2.834 & 5.769 \\
$y$ & 1740 & 8.096 & 0.506 & 7.252 & 9.180 \\
$y^{*}$ & 1740 & 6.949 & 1.517 & 3.885 & 11.603 \\
$e$ & 1740 & 0.101 & 2.726 & -2.953 & 7.816 \\
$t$ & 1740 & 0.405 & 0.073 & 0.048 & 0.521 \\
\hline
\end{tabular}

Table 2.

Panel unit root test results.

\begin{tabular}{cccccc}
\hline & LLC & Breitung & IPS & ADF-Choi & PP-Choi \\
\hline$e x$ & $1.14[0.87]$ & $1.57[0.94]$ & $-0.32[0.37]$ & $-0.18[0.43]$ & $-0.32[0.37]$ \\
$i m$ & $1.01[0.84]$ & $-3.50[0.00]$ & $6.13[1.00]$ & $6.25[1.00]$ & $5.99[1.00]$ \\
$y$ & $-0.45[0.33]$ & $5.34[1.00]$ & $-1.32[0.09]$ & $-0.89[0.19]$ & $2.64[1.00]$ \\
$y^{*}$ & $-8.01[0.21]$ & $1.18[0.88]$ & $0.60[0.73]$ & $0.52[0.70]$ & $2.43[0.99]$ \\
$e$ & $0.06[0.52]$ & $-0.99[0.16]$ & $-2.55[0.01]$ & $-2.62[0.00]$ & $-2.06[0.02]$ \\
$t$ & $-0.61[0.27]$ & $-2.82[0.00]$ & $1.65[0.95]$ & $2.20[0.99]$ & $2.59[1.00]$ \\
$\Delta e x$ & $-34.3[0.00]$ & $-14.36[0.00]$ & $-38.7[0.00]$ & $-28.80[0.00]$ & $-28.37[0.00]$ \\
$\Delta i m$ & $-45.3[0.00]$ & $-19.30[0.00]$ & $-46.55[0.00]$ & $-32.83[0.00]$ & $-33.71[0.00]$ \\
$\Delta y$ & $-4.33[0.00]$ & $-25.71[0.00]$ & $-2.56[0.01]$ & $-2.37[0.01]$ & $-20.37[0.00]$ \\
$\Delta{ }^{*}$ & $-22.4[0.00]$ & $-13.64[0.00]$ & $-25.1[0.00]$ & $-22.02[0.00]$ & $-22.71[0.00]$ \\
$\Delta e$ & $-32.2[0.00]$ & $-18.25[0.00]$ & $-28.5[0.00]$ & $-24.27[0.00]$ & $-23.84[0.00]$ \\
$\Delta t$ & $-23.52[0.00]$ & $-3.20[0.00]$ & $-22.0[0.00]$ & $-19.27[0.00]$ & $-33.12[0.00]$ \\
\hline
\end{tabular}

Note: Numbers in square brackets stand for $p$-values.

For the panel cointegration tests results presents in Table 3. The null of no cointegration is rejected by all of the Pedroni $(1999,2004)$ tests at the $1 \%$ level. The panel cointegration tests point to the existence of long run relationships between exports, foreign trade partners' income, exchange rate and trade cost, and between imports, domestic income, exchange rate and trade cost.

\section{Threshold Effect Test}

In the second step, we use the growth ratio of nominal exchange rate as a threshold variable to estimate the model. To determine the numbers of thresholds, the model (3) was estimated by least squares, allowing for (sequentially) zero, one, two and three thresholds. The test statistics F1, F2 and F3, along with their bootstrap p-value, are shown in Table 4.

As for the export equation, we find that the test for single threshold F1 (6.009) is strongly significant with a bootstrap $p$-value of 0.013 , and the test for a double threshold F2 (3.495) is significant, with a bootstrap $p$-value of 0.066 . On the other hand, the test for a third threshold F3 (2.958) is not close to being statistically significant, with a bootstrap $p$-value of 0.109 . We can conclude that there is strong evidence that there are two thresholds in the regression relationship. For the analysis of import equation, we also can find high evidence that there are two thresholds in the regression relationship. Therefore, the remainder of this paper, we work with these double threshold models.

\section{Threshold Estimated Value}

The point estimates of the two thresholds and their asymptotic $95 \%$ confidence intervals are reported in Table 5 . The estimates are 0.0179 and 0.0449 for export equation, -0.0071 and 0.0776 for import equation, which are very small or very values in empirical distribution of the growth ratio of the nominal exchange rate threshold variable. Thus the three classes of bilateral nominal exchange rate indicated by the point estimates are those with "very low exchange rate fluctuation", "very high exchange rate fluctuation" and "other". The asymptotic confidence intervals for the threshold are tight, indicating little uncertainty about the nature of this division.

More information can be learned about the threshold estimates from plots of the likelihood ratio function LR in Figures 1 and 2. The point estimates are the value of $\gamma$ at which the likelihood ratio hits the zero axis. It's interesting to examine the unrefined first-step LR, the point where the LR1 equals zero for the export equation, which occursat $\hat{\gamma}_{1}=0.0179$. There is a second major dip in the LR around the second-step estimate $\hat{\gamma}_{2}=0.0449$. For the analysis of import equation, we can also find the similar evidences in the Figure 2. Therefore, the single threshold likelihood conveys information suggests that there is 
Table 3.

Panel cointegration test results.

\begin{tabular}{cccccccc}
\hline & Panel V & Panel Rho & Panel PP & Panel ADF & Group Rho & Group PP & Group ADF \\
\hline Statistics & $1.32(4.82)$ & $-4.53(-8.24)$ & $-5.94(-9.30)$ & $-1.82(-3.75)$ & $-5.16(-8.15)$ & $-7.77(-10.8)$ & $-2.90(-4.28)$ \\
$p$-value & $0.09(0.00)$ & $0.00(0.00)$ & $0.00(0.00)$ & $0.03(0.00)$ & $0.00(0.00)$ & $0.00(0.00)$ & $0.00(0.00)$ \\
\hline
\end{tabular}

Note: Numbers in and out brackets stand for imports and export equations.

Table 4.

Threshold effect test results.

\begin{tabular}{ccccc}
\hline Model & Threshold effect test & Single threshold & Double threshold & Triple threshold \\
\hline \multirow{2}{*}{ Export equation } & F-statistics & 6.009 & 3.495 & 2.958 \\
& $p$-value & 0.013 & 0.066 & 0.109 \\
Import equation & F-statistics & 13.692 & 20.540 & 1.341 \\
& $p$-value & 0.000 & 0.000 & 0.260 \\
Critical value & $1 \%$ & 6.386 & 6.252 & 8.343 \\
& $5 \%$ & 4.174 & 3.923 & 4.220 \\
\hline
\end{tabular}

Note: The $p$-values of F-statistics are calculated by 10000 numbers of bootstrap based on empirical distribution.

Table 5.

The threshold estimated value.

\begin{tabular}{cccc}
\hline & & \multicolumn{2}{c}{ Double threshold effects } \\
\cline { 2 - 3 } & Threshold value estimator & $95 \%$ conf. int. & Threshold value estimator \\
\hline Export equation & 0.0179 & {$[-0.0018,0.0308]$} & 0.0449 \\
Import equation & -0.0071 & {$[-0.0308,0.0002]$} & 0.0776 \\
\hline
\end{tabular}

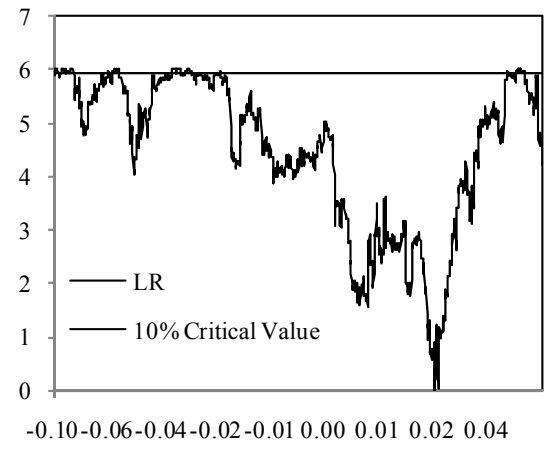

Figure 1.

LR test of export equation.

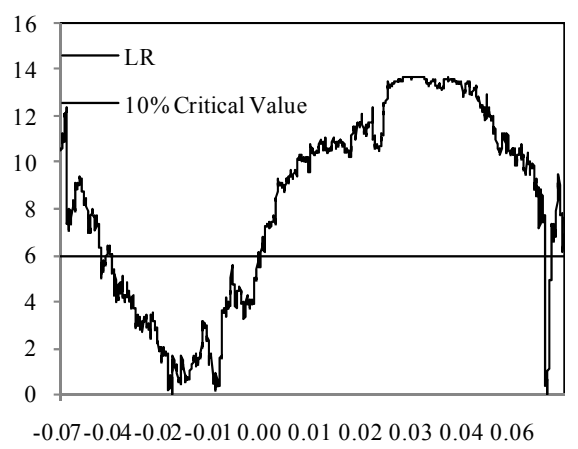

Figure 2.

The LR test of import equation. a second threshold in the regression.

\section{Empirical Results}

Tables 6 and 7 give the double threshold regression empirical results of the exports and import equation, respectively. We use ordinary fixed effect regression and double threshold regression to estimate the model (3) and (4). In order to overcome the heteroskedasticity of the model, the standard errors are White-corrected.

As is shown in Table 6 for the ordinary fixed effect regression model, the export flexibility of exchange rate is $-0.566 \%$, indicating that the exports decline $0.566 \%$, when the exchange rate appreciation $1 \%$. As for the estimated results of double threshold regression, we can find that the export flexibility of exchange rate would be $-0.563 \%$, when exchange rate appreciation is less than $1.8 \%$. However, when the exchange rate appreciation is between $1.8 \%$ and $4.5 \%$, the export flexibility of exchange rate would be $-0.591 \%$. Furthermore, when the exchange rate appreciation is higher than $4.5 \%$, the export flexibility of exchange rate would be $-0.569 \%$.

As is shown in Table 7 for the ordinary fixed effect regression model, the import flexibility of exchange rate is $0.382 \%$, indicating that the imports increase $0.382 \%$, when the exchange rate appreciation $1 \%$. As for the estimated results of double threshold regression, we can find that the import flexibility of exchange rate would be $0.328 \%$, when exchange rate depreciationis less than $1.8 \%$. However, when the exchange rate appreciationis between $-1.8 \%$ and $7.8 \%$, the import flexibility of exchange rate would be $0.401 \%$. Furthermore, when the exchange 


\section{L. CHEN}

Table 6.

Export equation: double threshold regression.

\begin{tabular}{ccccccc}
\hline & \multicolumn{3}{c}{ Ordinary fixed effect } & \multicolumn{3}{c}{ Double threshold } \\
\hline Variable & Beta & Rob-std & $t$ & Beta & Rob-std & $t$ \\
$y_{i t}$ & 1.29 & 0.047 & 27.32 & 1.30 & 0.047 & 27.47 \\
$t_{i t}$ & -24.12 & 0.771 & -31.29 & -24.11 & 0.769 & -31.36 \\
$e_{i t}$ & -0.57 & 0.0348 & -16.25 & & & \\
$e_{i t} \cdot I\left(q_{i t} \leq 1.8 \%\right)$ & & & & -0.56 & 0.035 & -16.21 \\
$e_{i t} \cdot I\left(1.8 \% \leq q_{i t} \leq 4.5 \%\right)$ & & & -0.59 & 0.036 & -16.66 \\
$e_{i t} \cdot I\left(q_{i t} \geq 4.5 \%\right)$ & & & -0.57 & 0.035 & -16.10 \\
\hline
\end{tabular}

Table 7.

Import equation:double threshold regression.

\begin{tabular}{|c|c|c|c|c|c|c|}
\hline \multirow[b]{2}{*}{ Variable } & \multicolumn{3}{|c|}{ Ordinary fixed effect } & \multicolumn{3}{|c|}{ Double threshold } \\
\hline & Beta & Rob-std & $t$ & Beta & Rob-std & $t$ \\
\hline$y_{i t}$ & 0.59 & 0.023 & 25.29 & 0.59 & 0.023 & 25.50 \\
\hline$t_{i t}$ & -19.35 & 0.658 & -29.43 & -19.32 & 0.651 & -29.69 \\
\hline$e_{i t}$ & 0.38 & 0.026 & 14.69 & & & \\
\hline$e_{i t} I\left(q_{i t} \leq-1.8 \%\right)$ & & & & 0.33 & 0.024 & 13.67 \\
\hline$e_{i t} \cdot I\left(-1.8 \% \leq q_{i t} \leq 7.8 \%\right)$ & & & & 0.40 & 0.025 & 16.04 \\
\hline$e_{i t} \cdot I\left(q_{i t} \geq 7.8 \%\right)$ & & & & 0.45 & 0.026 & 17.39 \\
\hline
\end{tabular}

Table 8.

Marshall-Lener condition results.

\begin{tabular}{cccccc}
\hline & \multicolumn{2}{c}{ Threshold model } & \multicolumn{2}{c}{ Linear model } & \multicolumn{2}{c}{ ML condition } \\
\cline { 2 - 5 } & $\lambda_{\text {ex }}$ & $\lambda_{\text {im }}$ & $\lambda_{\text {ex }}$ & $\lambda_{\text {im }}$ & $\left|\lambda_{\text {im }}\right|+\left|\lambda_{\text {ex }}\right|$ \\
\hline$q_{i t} \leq-1.8 \%$ & & & -0.57 & 0.38 & 0.95 \\
$-1.8 \% \leq q_{i t} \leq 1.8 \%$ & -0.56 & 0.33 & & 0.89 & 0.96 \\
$1.8 \% \leq q_{i t} \leq 4.5 \%$ & -0.56 & 0.40 & & 0.99 \\
$4.5 \% \leq q_{i t} \leq 7.8 \%$ & -0.59 & 0.40 & & 0.97 \\
$q_{i t} \geq 7.8 \%$ & -0.57 & 0.40 & & & 1.02 \\
\hline
\end{tabular}

rate appreciation is higher than $7.8 \%$, the import flexibility of exchange rate would be $0.452 \%$.

\section{Analysis of Nonlinear Marshall-Lener Condition}

Based on the estimated results of Tables 6 and 7, we can derive the Marshall-Lener condition in Table 8.

From the Table 8, we can see that Marshall-Lener condition would be $\left|\lambda_{i m}\right|+\left|\lambda_{e x}\right|=0.95$ for the linear model. As for the threshold regression model, the $\left|\lambda_{i m}\right|+\left|\lambda_{e x}\right|=0.89$ when exchange rate depreciation is less than $1.8 \%$, when exchange rate appreciation is between $-1.8 \%$ and $1.8 \%,\left|\lambda_{i m}\right|+\left|\lambda_{e x}\right|=0.96$, when exchange rate appreciation is between $1.8 \%$ and $4.5 \%$, $\left|\lambda_{i m}\right|+\left|\lambda_{e x}\right|=0.99$, when exchange rate appreciation is between $4.5 \%$ and $7.8 \%,\left|\lambda_{i m}\right|+\left|\lambda_{e x}\right|=0.97$, and when exchange rate appreciation is higher than $7.8 \%,\left|\lambda_{i m}\right|+\left|\lambda_{e x}\right|=1.02$. We can conclude that $\left|\lambda_{i m}\right|+\left|\lambda_{e x}\right|$ to be different, along with the fluctuations of the exchange rate. Furthermore, from the estimated results, we conclude that China's trade to thirty trade partners don't accord with Marshall-Lener condition, when the bilateral RMB exchange rate appreciation is less than $7.8 \%$ for the "very low exchange rate fluctuation" regime. However, when the bilateral RMB exchange rate appreciation is higher than $7.8 \%$ for the "very high exchange rate fluctuation" regime, the Marshall-Lener condition strongly holds, indicating that the domestic currency (RMB exchange rate) appreciation would reduce the China's current account surplus.

\section{Conclusion}

This paper examines the effectiveness of exchange rate fluctuations to imports and exports. Traditional studies use linear model as an application to analyze the elasticities of exchange rate on imports and exports. However, the impacts of exchange rate variations on imports and exports may be non-linear, therefore, we employ the threshold panel model, proposed by Hansen (1996, 1999), to estimate the threshold effects.

Firstly, we find that there is a second threshold in both im- 
port and export regression models. Exchange rate appreciation will lower exports, and devaluation will improve import, whereas both have threshold effects.

Secondly, the estimated results show that China's trade flows don't accord with Marshall-Lener condition, when the bilateral RMB exchange rate appreciation is less than $7.8 \%$. Whereas, when the bilateral RMB exchange rate appreciation is higher than $7.8 \%$, the Marshall-Lener condition strongly holds, indicating that the RMB exchange rate appreciation would deteriorate the China's international revenue.

Finally, this paper illustrates that the exchange rate variations on trade flows has threshold effect. As the RMB exchange rate to US dollar has experiences an appreciation of $22.2 \%$ from 2005Q3 to 2012Q1, which is higher than $7.8 \%$, therefore, the RMB appreciation will deteriorate China's current account by now. We must pay more attention to it, and make some changes or policies to deal with these problems.

\section{Acknowledgements}

This research is supported by Humanities and Social Sciences Youth Project of Chinese Ministry of Education (12YJC790006), National Social Sciences Foundation (12BJL057), Guangdong Planning Youth Project of Philosophy and Social Sciences (GD11YYJ01), and South China Normal University
Youth Teachers' Research Fund

\section{REFERENCES}

Bahmani-Oskooee, M., \& Niroomand, F. (1998). Long-run price elasticites and the marshall-lerner condition revisited. Economics Letters, 61, 101-109. doi:10.1016/S0165-1765(98)00147-5

De Silva, D., \& Zhu, Z. (2004). Sri Lanka's experiment with devaluation: VAR and ECM analysis of the exchange rate effects on trade balance and GDP. The International Trade Journal, 18, 269-301. doi:10.1080/08853900490518181

Hansen, B. E. (1996). Inference when a nuisance parameter is not identifed under the null hypothesis. Econometrica, 64, 413-430. doi: $10.2307 / 2171789$

Hansen, B. E. (1999). Threshold effects in non-dynamic panels: Estimation, testing and inference. Journal of Econometrics, 93, 345-368. doi:10.1016/S0304-4076(99)00025-1

Luis, S. (2012). Simultaneity between export and import flows and the Marshall-Lerner condition. Economic Modelling, 29, 879-883. doi:10.1016/j.econmod.2011.10.011

Wilson, P. (2001). Exchange rates and the trade balance for dynamic asian economies-Does the J-curve exist for Singapore, Malaysia and Korea? Open Economic Review, 12, 389-413. doi:10.1023/A:1017982901034

Mohsen, B.-O., \& Taggert, J. B. (1999). Bilateral J-Curve between US and her trading partners. Review of World Economics, 135, 156-165. 